\title{
Kuidas määratleda piire kultuuri- ja teadusmaastikul?
}

Tiiu Jaago

Käesolevasse teemanumbrisse on koondatud viis artiklit, milles käsitletakse piire ja piirialasid. Kuna autorid analüüsivad ajas ja ruumis kokkupuutumatuid sotsiaalseid ja kultuurilisi keskkondi, esindavad artiklid küllalt erinevaid vaatepunkte ja küsimuseasetusi. Samas võimaldab artiklite selline kooslus peatuda kahel teemal: sümboolsed piirid ühiskonnas ja interdistsiplinaarsus kui teadusvaldkondade vaheline piiriala.

Sümboolsete piiride käsitlustest nähtub piiride ja piirialade mitmetasandilisus ning seesmine vastuolulisus. Näiteks kasutatakse kaardil ja maastikul piiri tähistena erinevaid objekte-sümboleid, ent samal ajal on need omavahel üheselt seotud. Samuti ei kattu omavahel rahu- ja sõjaaegsed riigipiirid. Inimeste teadvuses (nagu ka jutustatud lugudes) esinevad need aga siiski samaaegsete ja omavahel põimunutena, kohakuti paljude muude piiridega. Ka võib sama inimeste rühma vaadelda kui osa kogukonnast, ent samas mingi tunnuse poolest neid teistest eristada (kuuljad versus vaegkuuljad ja kurdid, Eestis elavad eestlased versus väljarände kogemusega eestlased mujal maailmas). Eelnevast johtuvalt kerkib piiride määratlemisel esile ka see, kes on määratleja ja milliseid viise ta seejuures kasutab.

Teadusvaldkondade vahel olevate, peamiselt 20. sajandi algupooleks väljakujunenud piiride hajumist 20. sajandi lõpul on tähistatud selliste mõistetega nagu multidistsiplinaarsus, interdistsiplinaarsus, transdistsiplinaarsus. Neist enamlevinud on interdistsiplinaarsus, mida on kasutatud ka kui teadusvaldkondade vahelise koostöö üldmõistet. Kui neid koostöövorme siiski eristatakse, on selle aluseks töö eesmärgid, töövõtted, teaduskeel ja terminvara (mis minu kogemuste põhjal on eriti keeruline, sest samu mõisteid kasutatakse erinevates tähendustes, vt Jaago 2011; 2015) ning teoreetiline raam. Multidistsiplinaarsust seostatakse ennekõike teadusalade (või vastavate uurimuste) kõrvutamisega, interdistsiplinaarsust holistliku käsitlusviisi ja lõimumisega ning transdistsiplinaarsust piiride innovatiivse ületamisega, millega võib kaasneda nii ise- 
seisvate teadusalade taandumine kui ka uute kujunemine (vt nt Torop 2009: 16-17; Klein 2010; Alvargonzález 2011). Inter- ja transdistsiplinaarsuse esiletulekut 20. sajandi lõpul on põhjendatud nii teaduspoliitika muutumise kui ka teadlaste arvu suurenemisega. Neid arenguid iseloomustas kaks vastandlikku suunda: tihenes küll lähiteadusaladel tehtav koostöö, kuid samas suurendas see teadusala seesmist hargnemist (vt nt Weingart 2010). Folkloristika vaatepunktist võiks rõhutada näiteks kontekstide esiletulekut rahvaluule tõlgendamisel: rahvaluule esinemisolukorra ja tähenduste kirjeldamine tõi kaasa kasvava vajaduse kasutada teistel teadusaladel tehtud uurimusi (nt ajaloos, sotsioloogias, infotehnoloogias) ning rakendada folkloristlikus pärimusanalüüsis ebatraditsioonilisi allikaid (vrd nt Joyner 1989; Apo 2001; Kõiva 2008; Paal 2010; Valk 2015). Samal ajal hakkasid folkloristika raames kujunema uued suunad (nt tänapäeva folkloori, kohapärimuse, internetifolkloori, viipekeelse folkloori, pärimusliku ajaloo uurimine). Sellised arengud nõudsid folkloristilt varasemast teistsugust orienteerumist nii oma aines kui ka teadusmaastikul üldiselt. Varasemad koostöövormid, nagu nt folkloristika ja kirjandusteadus, ei toiminud interdistsiplinaarsuse põhimõttel, kuna nõukogude ajal suunati folkloristikat võtma kirjandusteaduse osana (vt Nekljudov 2003: 27-28). See põhjendab, miks interdistsiplinaarsel ajajärgul ei ole kirjanduse ja rahvaluule eelduspärane seos uurijaid koostööle märkimisväärselt inspireerinud. Kui sõjaeelsel perioodil pakkus rahvaluuleuurimisse kirjandusteadusest lähtuva pidepunkti August Annist (see puudutas regilaulude stiili uurimist ja oli toona viljakas idee), siis 1990. aastaks kujunenud olukorras piiras kirjandusteaduslike vahendite kasutamine rahvaluule uurimisel rahvaluule enda spetsiifika mõistmist (Annist 1936; Jaago 1993). Sellest nähtub, et teadusvaldkondade omavahelist seotust mõjutab oluliselt ka senine teaduse arengu lugu. Interdistsiplinaarsus on seega nii teoreetiline kontseptsioon kui ka teaduspraktikast lähtuv kogemus.

Käesolevas kogumikus võib interdistsiplinaarsust vaadelda kui teadlaste tööpraktikat. On selge, et teadusala piiri määratlemine või selle ületamine ei allu ainuüksi uurija tahtele. Seda eriti juhul, kui piire loob aines ise, näiteks keelekasutus, ajastutunnetus, analüüsimeetodid vms. Kuid üldiselt kutsub interdistsiplinaarsuse esile uuritava elukeskkonna ja selle tõlgenduse muutumine: johtuvalt ühiskonnamuutustest nihkub uurimisfookus, mis omakorda viib teadusala teoreetilise poole revideerimiseni. Samas ei eelda interdistsiplinaarsus vältimatult seda, et uurimus tuleks paigutada teaduste vahealale. Teatud arenguetapis muutub aktuaalseks hoopis distsipliini eripära taaskordne, ent uuenenud mõtestamine. Eriti juhul, kui otsitakse vastust küsimusele, mis koht on ühel või teisel teadusharul uuenenud teaduspildis, mis on ühe või teise teadusharu võimalused panustada interdistsiplinaarsesse koostöösse. 
Nii toob teadusvaldkondade piiride hajumine (interdistsiplinaarsus) kaasa ka vastupidise suuna - teadusharu identiteedi tugevnemise.

Siinses kogumikus arutlevad eelkirjeldatud aspektide üle Tuulikki Kurki (folkloristika roll interdistsiplinaarses koostöös), Beata Paškevica (Herderi ja tema kaasaegsete osa rahvalaulualase teadusmõtte kujunemises), Ülle Tarkiainen ja Tiiu Jaago (näide allikate ja meetodite kombineerimisest), Liina Paales (viipekeelne kogukond tänapäeva ühiskonnas).

Tuulikki Kurki vaatleb lähemalt piiri-uurimisse puutuvaid tekste. Rahvuskeskse kultuurikäsituse kriitika kaudu arutleb ta folkloristliku teooria uuenemisvõimaluste üle, mis omakorda juhib küsimuseni folkloristika võimalikust panusest piiri-uurimisse. Kriitiline lähenemisviis, kinnitab Kurki, pakub võimalusi kohandada teooriat nii, et seni tähelepanuta jäänud kultuuriilmingud jõuaksid teaduslikesse käsitlustesse. Kurki esindab seisukohta, et interdistsiplinaarsus rikastub distsipliinide kaudu: näiteks folkloristika saab interdistsiplinaarses piiri-uurimises kaasa rääkida just neil teemadel, kus teistel teadusvaldkondadel puudub kogemus ja ligipääs nt analüüsimeetodite puudumise tõttu. Kurki arutleb ka teooria ja praktilise kultuurianalüüsi seoste üle: piiri ja piiriala uurimist toetav teoreetiline raam pakub küll nägemisviise, kuid mitte selgitusi sellel tasandil, mida uurib folkloristika, kus iga uuritav olukord on konkreetne ja vältimatult eriline ega avane täielikult teoreetiliste skeemide kaudu. Näiteks Tuulikki Kurki teoreetilises artiklis esitatud rahvuskeskse kultuurikäsitluse kriitika ja selle vastandina esile tõstetud piiriala ja piiriolukorra kesksus osutub vastuoluliseks ka Eesti kontekstis. Ka eesti folkloristika on kujunenud paralleelselt ja läbipõimunult rahvusliku ühtsuse ja rahvusriigi ülesehitamise ideedega. Samas on eesti kultuur olnud alati käsitletav ka kui piiriala (mis Tuulikki Kurki artiklis esitatud teoreetilise raami ja täpsemalt rahvuskeskse kultuurikäsitluse järgi on kultuurita ala). Seda nii 19. sajandi käsitlustes, kus Eesti jääb vene ja saksa kultuuri vahealale (s.o mõlema suurrahva kultuuri mõjuline üleminekuala) kui ka Nõukogude Liidu perioodil, mil riigi- ja ideoloogiapiir domineeris muude piiride üle (vt nt Hooson 1994; Nõmm 2006). Ühtlasi on märgatud eesti kultuuri piirialast loomust ka kultuuri seespoolses vaates, kui kirjeldatakse eesti "identiteedi rebenemist" euroopa ja soome-ugri kultuuri vahel (vt nt Mikita 2016: 50, 34 jj). Siit tõstatub omakorda hulk küsimusi: kuidas teooria rakendub igal konkreetsel juhul; kes otsustab, kas tegemist on rahvuskeskse või piirialakeskse kultuuriga (nagu eelkirjeldatud Eesti näites). Arvestades sama nähtuse erinevaid tõlgendusvõimalusi (ja -praktikat) võib küsida, kas teoreetiline vastandamine (nt rahvuslik versus piirialast lähtuv kultuuri kirjeldus) on praktilises elus üldse võimalik, sest uurimise seisukohast võib olla tegemist pelgalt vaatepunkti valikuga?

Teist laadi interdistsiplinaarsuse näite pakub Ülle Tarkiainen. Tema pikaaegne töö talurahva ajaloo uurimisel on viinud teda kokku pärimustekstidega, 
mis ühel või teisel moel on aidanud tõlgendada ajaloodokumente. Kui üdiselt tõdetakse, et rahvaluule-tekstid lisavad ajalooallikatele inimesekeskse vaate, siis siinses artiklis need seosed täpsustuvad. 18. ja 19. sajandi sündmusi ja olukordi vahendavaid materjale võrreldes näitab autor ajaloodokumentides ja rahvaluules leiduvate andmete omavahelisi sobitumisi, kattumisi, täiendusi ja uue elutahu avamisi (faktid versus suhtumine ja hoiakud; seadused versus argieluline käitumine; nimed ja aastaarvud versus inimeste kirjeldused jms). Kuigi autor oma teadusvaldkonnast ei välju, muudab käsitluse interdistsiplinaarseks ebatraditsioonilise allikmaterjali kasutus ja ühtlasi analüüsist lähtuv uus teave käsitletava ühiskonna ja ajalooperioodi kohta.

Beata Paškevica artikkel pakub kultuuri- ja keeleteadlase sissevaate Herderi rahvalaulude kogumise ja avaldamise aega. Herderi pärand on käsitletav nii ajaloo, filosoofia, keeleteaduse kui ka folkloristika vaatepunktist. Herderist lähtub ka rahvaluule teadlik ja suunatud kogumine Eestis. Sellegipoolest ei pääse tänapäeva folkloristid Herderi ajastule ja selleaegsetele dokumentidele (uurimise jaoks vajalikele allikmaterjalidele) kuigi lähedale, seda piiravad nii keeleoskuse kui ka ajastutunnetuse puudumine. Selle käsitlusega seoses ilmneb veel teinegi ajaloost tulenev piirang. Nimelt sidus Herderi ja tema kaasaegsete tööd (balti)saksa kultuuriruum. Rahvuslik teadusmaastik aga muutis piire nõnda, et eesti folkloristid läti teemadega kuigivõrd ei tegelenud (nagu ka vastupidi). Läti laule ja kogujaid tutvustava artikli ilmumisega eesti keeles püütakse seda piiri taas pisutki ületada.

Liina Paales tutvustab kurtide kogukonna ja viipekeelse pärimuse uuemaid uurimissuundi. Ta ei kasuta oma artiklis piirirahva mõistet, ent Tuulikki Kurki artikliga kõrvutuses sobib Paalese käsitlus nimelt sellesse teoreetilisse kontseptsiooni. Vastavalt tuleb ka rahva ja piirirahva omavaheline seotus esile. Ühelt poolt võib näha vastandust kuuljad versus kurdid, mille järgi kurdid võiksid esindada piirirahvast. Teisalt aga on kuuljate ja kurtide maailm ühine. Mõlemate maailma kuuluvad nii meditsiin kui ka seadused, tehnika kui ka sotsiaalmeedia. Samas on kurtide kogukonnas kõikidel neil valdkondadel ainuomane tähendus ja roll. Kurtide kogukonna ja viipekeelse pärimuse uurimine on tekitanud vajaduse arendada viipekeelset terminoloogiat. Artikli üks osa ongi pühendatud eesti viipekeele akadeemilise sõnavara tutvustamisele.

Tiiu Jaago artikli teemaks on Teise maailmasõja aegsete põgenemisteekondade kujutamine 20. sajandi lõpul ja 21. sajandi alguses jutustatud elulugudes. Osalt haakub see teema ajaloo uurimisega (kui fookuses on ajalooline periood ja sellega seotud sündmustik), osalt interdistsiplinaarsete mälu-uuringutega (kui keskendutakse sündmuse meenutamisele ja tähendusele sündmusjärgsetel perioodidel, sh tänapäeval). Siinses artiklis on aga küsimuseks piiride ja piiriületuste esitusviisid. Eluloojutustuste analüüsiks on kasutatud kunstiliste piiriesituste pinnalt väljatöötatud lähenemisviisi piiripoeetikat. See võimaldab 
nihutada tähelepanukeset konkreetsetelt ajaloolistelt sündmustelt ja individuaalsetelt läbielamistelt üldisemale pinnale. Vähesel määral on seda artiklis ka rakendatud, pakkudes võrdluseks Läände põgenenute lugudele ka Eestisse põgenenud ingerlase, Eestist sõja alguses itta evakueerunu ja 1949. aastal küüditatu loo. Ajaloolise konkreetsuse hajutamine pidurdab stereotüüpide kinnistumist (n-ö tüüpilise põgenemise või küüditamise loo konstrueerimist) ja võimaldab esile tuua kodu kaotuse ja piiride ületuse kultuuridest lähtuvat kirjeldusviisi.

\section{Kommentaar}

Suur tänu piiride ja interdistsiplinaarsuse teemanumbri teokssaamisel autoritele ja ajakirja toimetusele, Kirsi Laurénile, Anu Kannikesele, Mare Kaldale, Merili Metsvahile, Kristi Metstele, Piret Voolaidile, Astrid Tuisule, Raili Nuginile. Eriti suur tänu Reet Benderile, kes toimetas Beata Paškevica artikli saksakeelsed tekstid ja tõlked, samuti Wiedemanni tõlkebüroole Tuulikki Kurki ja Beata Paškevica artikli ning Ann Kuslapile teeside tõlkimise eest.

Teemanumber on seotud Haridus- ja Teadusministeeriumi rahastatava projektiga “Traditsioon, loovus ja ühiskond: vähemused ja alternatiivsed diskursused” (IUT 2-43).

\section{Kirjandus}

Alvargonzález, David 2011. Multidisciplinarity, Interdisciplinarity, Transdisciplinarity, and the Sciences. International Studies in the Philosophy of Science 25 (4), lk 387-403 (doi: 10.1080/02698595.2011.623366).

Annist, August 1936. Meie rahvalaulu stiili küsimusi. Looming 7, lk 781-788.

Apo, Satu 2001. Rahvapärase mõtteviisi uurimine arhiivi- ja küsitlusmaterjali abil. Jaago, Tiiu (koost). Pärimus ja tõlgendus. Artikleid folkloristika ja etnoloogia teooria, meetodite ning uurimispraktika alalt. Tartu: Tartu Ülikooli Kirjastus, lk 218-233.

Hooson, David 1994. Ex-Soviet Identities and the Return of Geography. Hooson, David (toim). Geography and National Identity. Oxford: Blackwell, lk 134-140.

Jaago, Tiiu 1993. Kuldnaine. Tartu: Tartu Ülikool.

Jaago, Tiiu 2011. Rahvusvahelisuse ja interdistsiplinaarsuse mõju teaduskeelele argikultuuri uurimise näitel. Nemvalts, Peep (koost, toim). Eesti teaduskeel ja terminikorrastus. Tallinna Ülikooli Eesti Keele ja Kultuuri Instituudi toimetised nr 13. TLÜ Teaduskeskuse 1. köide. Tallinn: Tallinna Ülikool, lk 64-90.

Jaago, Tiiu 2015. Mõisted "mälu" ja "piir" interdistsiplinaarse ajajaärgu folkloristikas. Kivari, Kristel \& Västrik, Ergo-Hart (toim). Mälu. Meenutamine. Muistend. Folkloristide X talvekonverents, pühendatud Aino Laaguse 70. sünniaastapäevale. Tartu: Tartu Ülikooli eesti ja võrdleva rahvaluule osakond, lk 12-13. 
Joyner, Charles 1989. A Tale of Two Disciplines: Folklore and History. RichtmannAuguštin, Dunja \& Povrzanović, Maja (toim). Folklore and Historical Process. Zagreb: Institute of Folklore Research, lk 9-22.

Klein, Julie Thompson 2010. A taxonomy of interdisciplinarity. Frodeman, Robert \& Klein, Julie Thompson \& Mitcham, Carl (toim). The Oxford Handbook of Interdisciplinarity. Oxford: Oxford University Press, lk 15-30.

Kõiva, Mare 2008. Kahe kultuuri vahel: virtuaalne väliseesti kogukond. Labi, Kanni (toim). Paar sammukest... Eesti Kirjandusmuuseumi aastaraamat XXIV. Tartu: EKM Teaduskirjastus, lk 31-59.

Mikita, Valdur 2016. Hälin ja raev lingvistilises metsas. Loeng 21.09.2016 Tartu Ülikooli vabade kunstide kursusel Mõtterännak eestlaste elutundest, HVKU.01.003. Videosalvestus. Tartu: UTTV (http://www.uttv.ee/naita?id=24623 - 4. november 2016).

Nekljudov, Sergei 2003. Vene rahvaluuleteadus ja strukturaalsemiootilised uurimused. Jaago, Tiiu (koost). Pärimus ja tõlgendus. Artikleid folkloristika ja etnoloogia teooria, meetodite ning uurimispraktika alalt. Tartu: Tartu Ülikooli Kirjastus, lk 26-36.

Nõmm, Jelena 2006. The Baltic Region in Surveying and Ethnographic Materials of "The Illustrated Gazette" (1858-1887). Aalto, Nancy \& Reuter, Ewald (toim). Aspects of Intrercultural Dialogue. Theory, Research, Applications. Köln: SAXA Verlag, lk 289-297.

Paal, Piret (koost) 2010. Inimene, tervis ja haigused. Terviseteemaline artiklikogumik "Medica". Tänapäeva folkloorist 9. Tartu: EKM Teaduskirjastus.

Torop, Peeter 2009. Kultuuri analüüsitavusest. Acta Semiotica Estica VI, lk 11-41.

Valk, Ülo 2015. Kui muistendist saab fiktsioon. Žanriajaloolisi märkusi. Keel ja Kirjandus 8-10. Erinumber Lõputu rahvajutt (toim Risto Järv), lk 541-555 (http://kjk.eki.ee/ee/ issues/2015/8-9/681 - 4. november 2016).

Weingart, Peter 2010. A short history of knowledge formations. Frodeman, Robert \& Klein, Julie Thompson \& Mitcham, Carl (toim). The Oxford Handbook of Interdisciplinarity. Oxford: Oxford University Press, lk 3-14.

\section{Summary}

\section{How to specify borders in cultural and research landscapes?}

Tiiu Jaago

Keywords: border, interdisciplinarity, multidisciplinarity, transdisciplinarity

Introduction into the special issue dedicated to borders and border areas. As the authors analyse social and cultural environments that are not in contact in time or space, the articles represent rather different viewpoints and ways of raising questions. Such a range of articles, however, enables dwelling on two topics: symbolic borders in society and interdisciplinarity as a border area between different domains. 